\title{
Design Suitable Charge Controller for Solar Tree
}

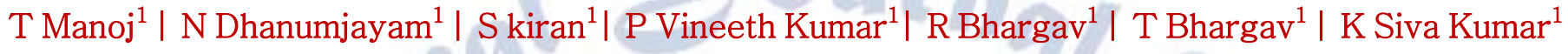 \\ ${ }^{1}$ Department of EEE, Aditya Institute of Technology and Management, Tekkali, Andhra Pradesh, India.
}

\section{To Cite this Article}

T Manoj, N Dhanumjayam, S kiran, P Vineeth Kumar, R Bhargav, T Bhargav and K Siva Kumar, "Design Suitable Charge Controller for Solar Tree", International Journal for Modern Trends in Science and Technology, Vol. 06, Issue 07, July 2020, pp.:91-95; https://doi.org/10.46501/IJMTST060714

\section{Article Info}

Received on 19-June-2020, Revised on 22-June-2020, Accepted on 30-June-2020, Published on 13-July-2020.

\section{ABSTRACT}

Solar modules, power electronic equipments which include the charge-discharge controller, the inverter, the test instrumentation and the computer monitoring, and the storage battery or the other energy storage and auxiliary generating plant make-up of the photovoltaic system which is shown in the thesis. PV system design should follow to meet the load supply requirements, make system low cost, seriously consider the design of software and hardware, and make general software design prior to hardware design in the paper. To take the design of $P V$ system for an example, the paper gives the analysis of the design of system software and system hardware, economic benefit, and basic ideas and steps of the installation and the connection of the system. It elaborates on the information acquisition, the software and hardware design of the system, the evaluation and optimization of the system. Finally, it shows the analysis and prospect of the application of photovoltaic technology in outer space, solar lamps, freeways and communications.

KEYWORDS: solarpanels, LED lights, batteries, cables.

Copyright (C) 2014-2020 International Journal for Modern Trends in Science and Technology

DOI: https://doi.org/10.46501/IJMTST060714

\section{INTRODUCTION}

Energy is material base of the economic development. To ensure the sustainable development of national economy, there must be the energy which can be continually provided for support. In the past 200 yearsthe energy system based on coal, oil, natural gas and other fossil fuel has greatly promoted the development of human society. However, material life and spiritual life is increasing, the awareness of serious consequences brought from the large-scale use of fossil fuels is increasing at the same time: depletion of resources, deteriorating environment, in addition to all of the above, it induce political and economic disputes of a number of nations and regions, and even conflict and war. After in-depth reflection of the development process of the past, human advance seriously the future path of sustainable development. Today in the 21 st century, there is no a problem as important as a sustainable energy supply, especially for the benefit of solar energy development and has been highly concerned by all mankind. Around the world are faced with limited fossil fuel resources and higher environmental challenges, it is particularly important to adhere to energy conservation, improve energy efficiency, optimize energy structure, and rely on scientific and technological progress, development and utilization of new and renewable sources. In this paper, starting from the composition of the solar photovoltaic system, working principle and the 
photovoltaic power generation system design approach and design elements expatiate the steps and the idea of photovoltaic system design. Instructions for the applications of solar photovoltaic system in various aspects.

The reduced environmental impact of using solar energy in comparison to fossil fuels and other non-renewable resources has been noted and lauded. Understanding how solar energy works is important, since its benefits are unfortunately rarely compared to other green and sustainable sources. Hydroelectricity, wind turbines, geothermal energy and biomass are all environmentally friendly alternatives to traditional fuels. Hydroelectricity, although effective, does not benefit home usage since it is generally supplied through the use of large dams. Not only are dams expensive to build, but there are also many details to take into account before building one and the impact of the surrounding environment should be evaluated. Building a dam has the ability to alter an entire ecosystem and must be done with proper care and consideration. Photovoltaic panels will not change the environment and are small in comparison to dams. One of the advantages of solar power is its versatility. A land or roof installation can be set up in regions that many would think don't receive enough sunlight. Wind turbines can be another effective way to generate energy, but the advantages of solar power prevail over this method as well. Although the initial power gathered from wind is less expensive to produce, wind turbines require much more maintenance than photovoltaic cells. They are also more disruptive than their solar counterpart, since they are prone to making lots of noise. While PV panels can be installed on rooftops, a wind turbine is better suited for open and spacious areas. Traditionally, geothermal energy is restricted from becoming widespread by its reliance on being near tectonic plates. Advancements in technology may make geothermal energy more accessible in the future. Currently, another of the advantages of solar power is that it is effective anywhere in the United States. The use of biomass, such as the burning of wood, waste, alcohol fumes, or landfill gases produces less waste energy than fossil fuels or coal. Unfortunately, biomass creates volatile organic compounds, carbon monoxide and nitrogen oxides. On the positive side, its pollution is modest in comparison to traditional fuels. Photovoltaic cells prove superior again in that they create no emissions and do not require land that could be used for crops. The aforementioned green energy sources are better than fossil fuels and beneficial to taking some of the strain off the environment. The sustainable energy gained from the sun is still superior in quite a few areas. Solar energy can be used for large installations. It can also be created for a smaller scale and affordable enough for home use. Once installed, a home energy system requires very little upkeep, adjustment or maintenance. While dams and wind turbines have to be placed with consideration to their effects on the surrounding area, PV panels only need to be set up with the areas that receive the most sun.

\section{SOLAR PHOTOVOLTAIC SYSTEM AND OPERATION PRINCIPLE}

Solar photovoltaic system is power generation system of translating solar radiation into electrical energy directly using solar cell based on photovoltaic effect. Solar energy resources are dispersive and available everywhere, so solar energy photovoltaic power generation system is particularly suitable for use as an independent power supply. Solar photovoltaic system mainly includes three parts: solar components; power electronic equipment such as charge-discharge controller, inverter, test instrumentation and computer control; battery or other energy storage and auxiliary power generation equipment, as shown in Fig1. The working principle of photovoltaic power supply system is that the electricity produced from the solar component will charge for the battery controlled by the controller, directly to the load power supply in the context of meeting the load demand under the sunlight. The battery supply power for the DC load under the control of the controller if the sunlight is lack or at night. The converter is need to translate AC into DC for the photovoltaic system with AC load.

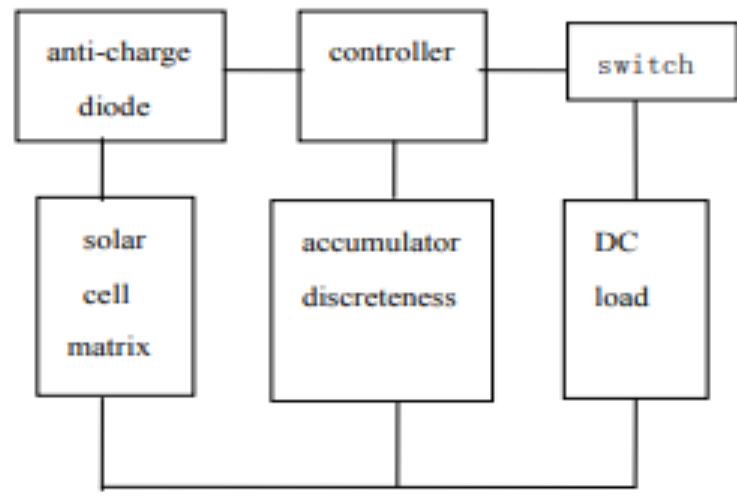

Figure 1: Solar photovoltaic system

Solar photovoltaic components: 


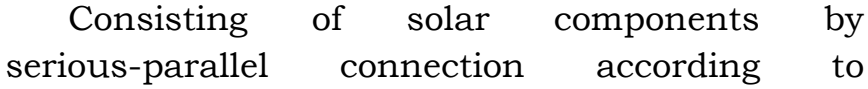
requirement converting solar radiation into electrical energy under the light, it is the core component.

\section{Anti-recoil diode}

Choose the appropriate rectifier diodes as anti-anti-charge in diode Solar photovoltaic system. Its role is to ensure the battery can discharge through the solar cell matrix when the solar cell matrix don't generate electricity or appear short-circuit fault in the rainy days and nights.

\section{Controller and Inverter}

Controller is the equipment of control and management solar photovoltaic system, its control has the two ways of logic control and computer control. The main complete function: First, detection of a variety of PV systems installations and the state and parameters of all modules for the system, provide the basis for judgement, control and protection; Second, optimal charging control for battery, the controller determine the optimal charging method based on the current status of battery in the state of solar energy resources, in order to achieve efficient, rapid charging, and fully consider the battery life with the charge method; Third, the management of battery discharge process; Forth, provide protection for electrical equipment connected to photovoltaic electricity system to prevent damage of the PV system or electrical equipment; Fifth, fault diagnosis positioning and operation instructions. Inverter is the equipment turned DC into AC. Because the output of solar cell and battery is direct current, the inverter is indispensable when the load is AC load. The technical requirements of the inverter are: steady output voltage and frequency, adjustable in a certain range; a certain over loading capability; output voltage waveform with the smaller harmonic components.

\section{Measuring Equipment}

According to the scale of solar photovoltaic systems, there are different detection and measurement of photovoltaic power generation system. Only simple measurements are carried for the small-scale solar photovoltaic systems, but more measurement parameters are called for large and medium-sized solar photovoltaic power plants, and industrial power systems, such as: solar power system communication, pipeline cathodic protection systems.

\section{DESIGN PRINCIPLES OF SOLAR PHOTOVOLTAIC SYSTEM}

The overall principles of designing of solar photovoltaic system are: under the premise of electricity supplying meeting the load, the economy of the system is the best. Photovoltaic power generation system can be divided into software design and hardware design, usually software design is earlier than the general hardware. Software design includes the investigation of the load and estimating of load power consumption, calculation of radiation of solar cell surface matrix, the calculation of solar cell components and battery capacity, and the optimization match between them, the best calculation of square angle, the prediction of system performance and the analysis of cost-effective. Hardware design include the selection and design of the load, the choice of solar cells and batteries, the design of components and support of the array, the selection and design of inverter, as well as the selection and design of the control and measurement system.

\section{Solar tree:}

As we know trees are present in nature and they can produce their own food material by the process called PHOTOSYNTHESIS. It is the process by which the green plant collects energy from sun and the water present in soil at the day time and can produces their own food material. By this process they are indirectly providing food to the human society because we are depending on the green plants for our food directly or indirectly. Here we are considering the example for understanding about the solar tree.

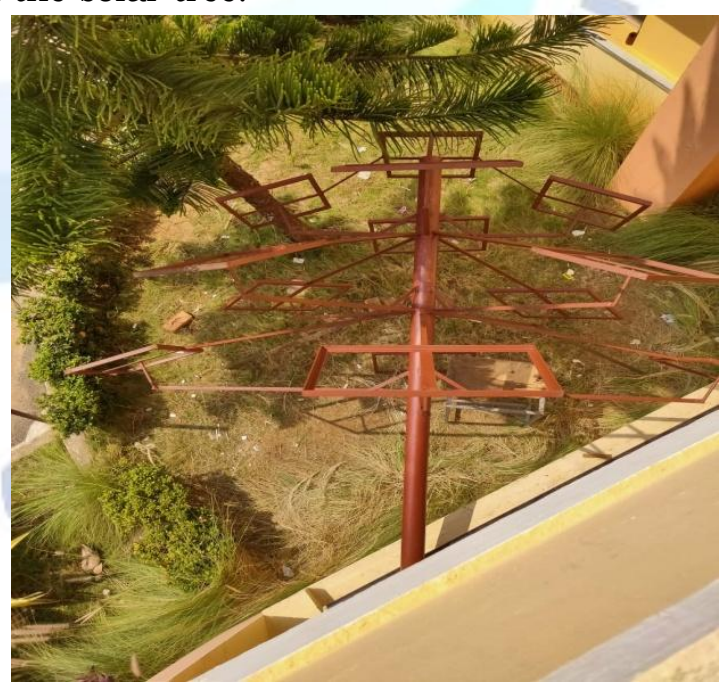

Figure 2: Structure of Solar Tree

This is a tree in which the stems connected acts as the branches of the tree and the solar panels are like the leaves. Green leaves are producing food materials for human beings likewise this leaves are 
producing energy for the society. So it is very appropriate to called it as a tree. It has same methods are used Spiralling Phyllataxy It is a technique used in designing of solar tree. It provides the way to help the lower panels from the shadow of upper ones, so that it can track maximum power from sun. Batteries are charged during the day time. LEDs are automatically switched on these are used to indicate how much charge/energy remain left Batteries are also used to store the energy so that we can use it at night and in cloudy days when no sunlight is there.

\section{Pipes}

Solar PV modules are mounted on a single tall pole made of Galvanized Iron (GI) pipe having diameter 3 inches and 12 feet height. The branches of the solar tree are made of cast iron and are square in shape. The branches are tilted at an angle of 40-450 for acquiring more amount of sun rays.To get the required power for the small household purpose total of 11 branches are being installed containing solar panels at the tip and the top of the pole consists of one solar panel having tilting mechanism to tilt the topmost solar panel at different angles through the day. The fig. 3 shows the circular stem of the solar tree.

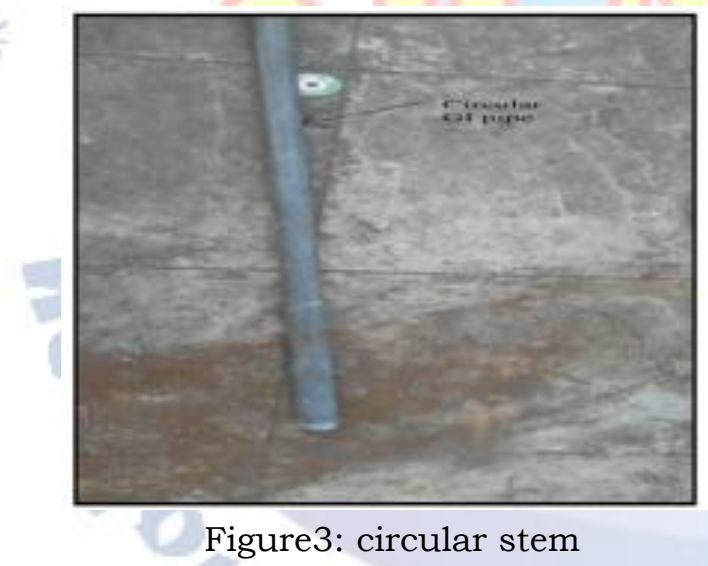

Battery:

Here the use of $12 \mathrm{~V}$ lead acid batteries is made. Despite having a very low energy to weight ratio and a low energy to volume ratio, its ability to supply high surge currents means that the cells have a relatively large power to weight ratio. These features, along with low cost, make it attractive. As battery used here isof less cost compared to newer technologies, lead acid batteries are widely used even when surge current is not important and other designs could provide higher energy densities. Large format lead acid designs are widely used for storage in backup power supplies in cell phone towers. Due to this reason lead acid battery is selected for storing of power from the solar panel. The fig. 4 shows the lead acid battery.

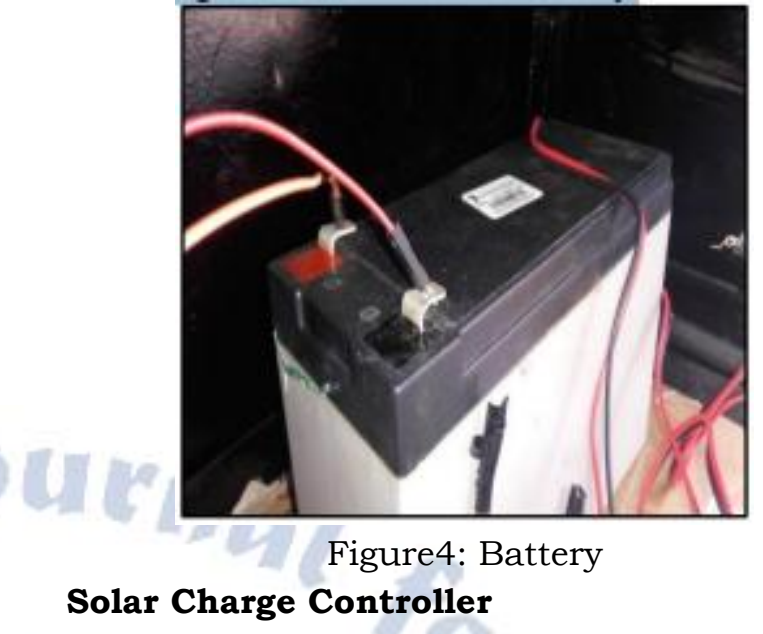

A charge controller, charge regulator or battery regulator limits the rate at which electric current isadded to or drawn from electric batteries. It prevents overcharging and may protect against overvoltage, whichcan reduce battery performance or lifespan, and may pose a safety risk. It may also prevent completely draininga battery or perform controlled discharges, depending on the battery technology to protect battery life. The fig. 5shows the solar charge controller.

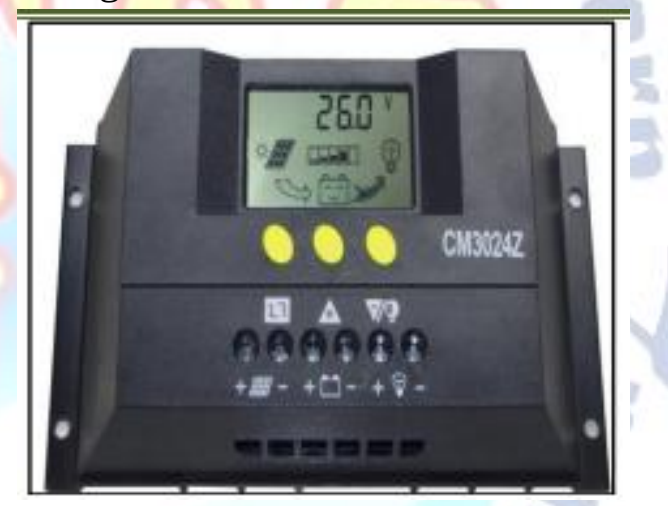

Figure 5: Solar Charge Controller

\section{Design and calculations:}

The following parameters are considered for the construction of solar tree. The length of the stem is $3.65 \mathrm{~m}$ from ground to the top and the diameter of the stem is $0.055 \mathrm{~m}$. There are 11 branches and angle of each branch is 400 from its stem. The angle of solar panel fixed at the top of each branch is 450 to its branches. The base area of solar tree is $121.92 \mathrm{~m} 2$ and it will be grounded.

\begin{tabular}{|l|c|c|c|}
\hline LOAD & Wattage & Quantity & Total \\
\hline computer & $80 \mathrm{~W}$ & 6 & $\begin{array}{l}6 \times 80= \\
480 \mathrm{w}\end{array}$ \\
\hline Fan & $80 \mathrm{~W}$ & 4 & $320 \mathrm{w}$ \\
\hline Total load & $160 \mathrm{~W}$ & 10 & $800 \mathrm{w}$ \\
\hline
\end{tabular}



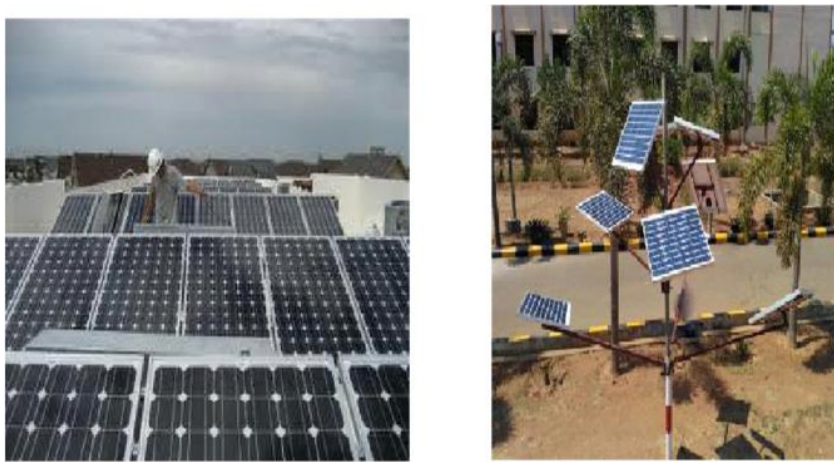

Figure 6: Experimental Diagram for Solar Tree

\section{Conclusion}

Solar tree is a revolutionary urban lighting concept that represents a perfect symbiosis between pioneering design and cutting edge eco compatible technology. The tree design made 50\% more electricity andthe collection time of sunlight was up to $50 \%$ longer. It helps the environment, saves money, cheap to use in any homes .It's free and last for lifetime and environment friendly. To fulfill the increasing energy demand of the people, saving of land, the solar tree concept is very successful one and should be implemented in India to provide electricity without the problem of power cut and the extra energy can be provided to the grid. Solar tree could be the best solution for the power needs.

\section{REFERENCES}

[1] J.A. Jakubiec, C. F. Reinhart, "A method for predicting citywide electricity gains from photovoltaic panels based on LiDAR and GIS data combined with hourly Daysim simulations," Sol. Energ., Vol. 93, pp. 127-143, Jul. 2013.

[2] Karl F. Warnick "A Bio-Inspired Patch Antenna Array Using Fibonacci Sequences in Trees", IEEE Antennas and Propagation Magazine Vol 55, no. 5, oct 2013.

[3] Abhishek Agarwal, Vineet Kumar Vashishtha, S.N. Mishra," Solar Tilt Measurement of Array for Building Application and Error Analysis",International Journal of Renewable Energy Research, IJRER, Vol. 2,No. 4,

[4] Immanuel Alphonse, Dr. S. HosiminThilagar, F. Bright Singh," Design of Solar Powered BLDC Motor Driven Electric Vehicle",International Journal of Renewable Energy Research

[5] Rustu Eke, SenerOktik," Seasonal Variation of Internal Parameters of an Amorphous Silicon(a-Si) Thin film Photovoltaic Module"International Journal of Renewable Energy Research2012

[6] .FarshidMostofi, Hossein Shayeghi," Feasibility and Optimal Reliable Design of Renewable Hybrid Energy System for Rural Electrification in Iran", International Journal of Renewable Energy Research, IJRER, vol.2, No.4, 2012.

[7] Markvart, T. Photovoltaic Solar Energy Conversion. Proceedings of the Energy for Europe. 7th - 14th July. Strabourg. 2002.
[8] P.Baruch. A two-level system as a model for photovoltaic solar cell. J. Appl. Phys. Vol 57. 1347. 1985.

[9] L.L.Bucciarielli. The effect of day -to-day correlation in solar radiation on the probability of loss of power in a stand - along photovoltaic energy systems. Solar energy. Vol 36. 11. 1986

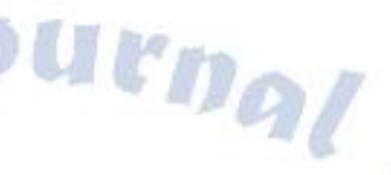

